\title{
INTERNAL COMPETITION AND COOPERATION AT ART MUSEUMS: A QUALITATIVE EXPLORATION
}

\author{
Sandra Mottner, Western Washington University \\ John B. Ford, Old Dominion University \\ Theresa Kirchner, Hampton University
}

\begin{abstract}
Internal competition and internal cooperation and/or collaboration are constructs that are defined most often in managerial literature. The two constructs are generally seen as having a poor influence on outcomes in the case of internal competition and more positive outcomes in the case of cooperation/collaboration. However, outcomes in the nonprofit world are not so easily defined as in for-profit businesses. Further, the concepts on internal competition and internal cooperation are not well understood in the nonprofit arena. This research explores the concepts using qualitative in-depth interviews from a variety of U.S. non-profit art museums in order to begin the development of a better understanding of how the presence, intensity and nature of internal competition and internal cooperation manifest themselves.
\end{abstract}

The art museums studied include a variety of art museum venues from vast collections to single medium collections. Some are funded or partially funded by government agencies. Some are solely funded by donations and grants. The footprint and collection size as well as amount of paid and volunteer staff varied. At each art museum three perspectives were gathered and analyzed. The subjects of the in-depth interviews included an executive with strategic responsibilities, someone with marketing and/or financial support responsibilities and then someone with collections or curatorial responsibilities.

What developed from a synthesis of these interviews was a relatively complex view of the nature and intensity of internal competition and cooperation. In general, internal cooperation that had a strong understanding of and unity around a central mission seemed to be most effective in achieving the art museum's mission. Internal competition was more complex in nature. Depending on personal characteristics such as personal ego, the strength of the museum's mission as understood by various players and a variety of other factors, internal competition appeared to play a role in both detrimental effects and/or positive effects in terms of art museum mission achievement.

References available upon request. 